\title{
Estimating the Impacts of Area Regeneration Programmes in Scotland on Health and Unemployment: a quasi-experimental approach
}

\author{
Daryll Archibald $1 *$, Zhiqiang Feng 2 , Elspeth Graham ${ }^{3}$ \\ 1 La Trobe University \\ 2 University of Edinburgh \\ 3 University of St Andrews
}

\begin{abstract}
The last three decades have seen significant investment in area-based initiatives in the UK to regenerate areas experiencing multiple disadvantage. However, there is a dearth of robust evidence on the impacts that area regeneration has on residents' lives. This is particularly so in the case of the Scottish Area Regeneration Partnership (SARP) Programmes initiated in the mid-1990s, the original evaluation of which was beset by a lack of baseline data and poor data collection through the life of the programmes. This study investigated if residents who lived in SARP areas had improved health and employment outcomes compared to individuals living in similarly disadvantaged areas that had not been subject to regeneration over a ten-year period (1991-2001). A quasi experiment was undertaken using data from the Scottish Longitudinal Study. Propensity score matching was used to identify comparator areas and a Difference in Differences analysis was conducted to investigate the impacts of the SARP programmes for three outcomes: limiting long-term illness, hospital admissions and unemployment. No positive (or negative) programme impact was found on any of the outcomes assessed. Thus, residents in SARP areas over the study period did not see their health and employment prospects improve compared with residents in similarly disadvantaged non-regeneration comparator areas.
\end{abstract}

Keywords: area regeneration, health, unemployment, programme evaluation, quasiexperiment, Scotland.

\section{Introduction}

Area regeneration programmes attempt to target and reverse physical, social and economic causes of decline to create thriving communities. Socio-economic outcomes like employment opportunities, housing quality and educational attainment are all routinely targeted in area regeneration strategies (Cole et al., 2007). Improvements in these outcomes may favourably alter the distribution of the determinants of health (Parry, 2004), however, conclusive empirical evidence pertaining to the positive impacts of area regeneration remains elusive (Lawless, 2013). 
p. 2. Estimating the Impacts of Area Regeneration Programmes in Scotland on Health and Unemployment: a quasi-experimental approach

A systematic review investigating the public health impacts of area regeneration programmes in the United Kingdom (1980-2004) by Thomson et al. (2006) concluded that there is little evidence of the impact of national area regeneration investment on socio-economic or health outcomes. A more recent review on this subject, by McCartney et al. (2017) also found that the evidence base for the impacts of area regeneration on health and unemployment is limited and requires better quality evaluation studies to be undertaken to understand the contribution that area regeneration programmes can make to population health.

The findings of these reviews have helped to stimulate key debates, which this paper aims to contribute to, regarding how area regeneration programmes can be more rigorously evaluated, and more generally, how effective area-based initiatives can be in improving conditions in disadvantaged communities (e.g. Curtis, Cave and Coutts, 2002; Rhodes et al., 2005; Lawless, 2012).

In Scotland, the main national regeneration flagship programmes in the 1990s and 2000s, the Scottish Area Regeneration Partnerships (SARPs) stand out as holistic (physical, social and environmental) area regeneration initiatives that have been subject to little evaluation (Petticrew et al., 2008). The SARP approach to area regeneration in Scotland ran from 1996 to 2006 and aimed to tackle multiple deprivation in 21 of Scotland's most disadvantaged communities (Tyler et al., 2001).

These programmes focused on investment in housing (both renewal and new build), improving green space, promoting community safety and social inclusion, providing education and training programmes for the unemployed. The SARP approach also involved delivery of specific health promotion initiatives such as smoking cessation, improving rates of breast feeding, and improving the diet and nutritional knowledge of the local population (Archibald, 2014).

The performance of the SARP programmes was originally planned to be monitored via 16 core indicators covering population, housing, crime, employment and training, education, health and community engagement. However, evaluation of the programmes was beset by a lack of baseline data and poor data collection generally (Petticrew, 2008).

The objective of this study is to use quasi-experimental methods to evaluate the impact that the SARP programmes had on the health and employment opportunities of residents who experienced the programme. The study aims to contribute to the key debates stated above, by adding to a growing literature demonstrating how quasiexperimental methods can address some key shortcomings of previous evaluations of area regeneration programmes in order to add rigour to the evidence base. These shortcomings will be discussed in the following section. The core research question of the study is - Did living in SARP areas have a positive or negative impact on the likelihood of residents suffering from morbidity or being unemployed compared with residents living in a comparator area that did not receive the programme?

This paper is organised in the following fashion. The next section will present a short literature review focusing on the problems associated with attempting to rigorously evaluate regeneration programmes. This will be followed by a section that outlines the key features of the SARP programmes. The methodological strategy of the study will then be described, followed by the presentation of the study results. An in-depth discussion of these results will then be presented before a final conclusion is stated. 
p. 3. Estimating the Impacts of Area Regeneration Programmes in Scotland on Health and Unemployment: a quasi-experimental approach

\section{Evaluating area regeneration programmes}

The lack of robust evidence demonstrating positive impacts of area-based regeneration has been widely lamented (e.g. Dabinett et al., 2001; Atkinson et al., 2006; Lawless et al., 2012), meaning that policy makers have been unable to draw firm conclusions as to how area-based initiatives impact on residents. This lack of evidence has been attributed to many factors. A heavily cited paper by Rhodes et al. (2005) pointed to three central issues that have constrained the development of evidence in this field: (1) A limited understanding of the theory of change underpinning regeneration programmes; (2) inadequate methods; (3) a focus on process and outputs as opposed to a focus on key outcome measures. The following will briefly discuss each of these three issues in turn.

\section{Theory of change}

A key criticism of area regeneration programmes has focused on poor articulation of theory of change regarding how programme initiatives can work to produce better outcomes for communities (Rhodes et al., 2005; Ying Ho, 1999). This is a charge which can be levelled against the SARP programmes and other similar holistic programmes initiated in the mid-to late 1990s in the UK such as the Single Regeneration Budget (SRB) in England and the New Life for Urban Scotland (NLUS) initiative (Thomson et al., 2006), and to a lesser extent, the New Deal for Communities (NDC) programme in England (Lawless, 2006).

The absence of a well-developed theory of change is particularly problematic with regard to holistic regeneration programmes as it is important for evaluations to be able to account for the complexity and interplay across the diverse range of economic, social and physical interventions undertaken as part of these large programmes. Indeed the physical, social and economic characteristics of holistic programmes are seen to interlink to some extent and may be causally related. For example, there is an established link between poor physical conditions and social deprivation, whilst economic success may be the foundation for urban prosperity and quality of life (Roberts and Sykes, 2000: 12). Thus many holistic regeneration programmes require detailed theories of change to inform the thrust of rigorous evaluations.

However, Lawless (2006) argued that the environment within which large holistic programmes have had to operate in has impeded the development of detailed theories of change. Lack of both relevant baseline data and a solid evidence base from which to develop programmes that will likely produce desired outcomes have been two significant challenges to the process of developing meaningful theories of change. Moving beyond this, Thomson et al. (2007) argued that if a programme has no theory of change articulated then evaluators can develop and test their own theory based on programme documentation, ensuring that selected outcomes are (as far as possible) in line with the goals and objectives of programmes. Indeed, recent evaluations of area regeneration programmes, such as that undertaken by Ploegmakers and Becker (2015), focusing on brownfield regeneration programmes in the Netherlands, used policy documentation to identify underlying assumptions regarding how the programmes were intended to work. This approach has been adopted in the present analysis of the SARP programmes' impact on health and unemployment.

\section{Methodological challenges to robust evaluations}

In order to build the evidence-base on the impacts of area regeneration programmes, calls have been made to introduce quasi-experimental designs, natural 
p. 4. Estimating the Impacts of Area Regeneration Programmes in Scotland on Health and Unemployment: a quasi-experimental approach

experiments and (if possible) randomised controlled trials to more rigorously assess the health and other impacts of regeneration interventions (e.g. Wanless, 2004; Petticrew et al., 2005; Des Jarlais et al. 2004; Rhodes et al., 2005; Thomson et al., 2006, 2007). However, there are well-documented difficulties associated with attempts to rigorously evaluate area regeneration practices. For example, Petticrew et al. (2005) stated that area-based regeneration is often not amenable to randomisation for practical and political reasons. For example, practical difficulties would arise if a researcher has no control over how a government area regeneration programme is rolled-out, and it would be politically problematic and ethically dubious for a loca authority to attempt to withhold a possibly beneficial intervention from a control group.

However, there are prominent examples from the USA where randomisation has been used. For example, the Moving to Opportunity programme which began in 1994 was a randomized controlled trial in which families from public housing in high-poverty neighborhoods were moved into private housing in near-poor or non- poor neighborhoods, with a subset remaining in public housing (Leventhal and Brooks-Gunn, 2003). Families in disadvantaged areas were randomised using a lottery system which assigned them to one of three groups: an experimental group who received a Section 8 voucher (a voucher that provides rent subsidies to purchase approved housing in the private market (Leventhal and Brooks-Gunn, 2003)) and mobility counselling, but who had to move to a low poverty neighbourhood; a Section 8 group who received the voucher only, and had no restriction on where they moved to; and a control group who did not receive a voucher or any other assistance (Kearns et al., 2009). This approach has its critics for denying assistance to individuals who may benefit from the intervention (e.g. Clark, 2008), however all participants in the MTO programme provided informed consent (Feins et al., 1996) and thus were well aware that they may not receive assistance.

In the UK, approaches to evaluating the impact of regeneration interventions by randomising residents to treatment and control groups have generally not been pursued with regard to the large holistic programmes that have been rolled out since the 1990s. Petticrew et al. (2005) have thus argued that, researchers can partially "fill the gaps" in knowledge by exploiting opportunities offered by quasi-experimental approaches to evaluation. Nevertheless, there are key difficulties in designing quasiexperimental evaluations. For example, Thomson (2008) stated that conducting community-based quasi-experimental evaluations that are powered to detect small impacts among individuals over long periods are neither straightforward from a pragmatic point of view nor cheap. Thomson (2008) further point to issues of being unable to control the timing of interventions and problems of increasing attrition in deprived communities likely to be targeted by area-based interventions.

Attempts to provide an estimation of the counterfactual (i.e. what would have happened in the absence of the initiative) to establish average intervention effects is a further challenge that has limited previous evaluations (Lawless et al., 2008). It is essential that treatment and control groups have comparable characteristics related to treatment assignment and the outcome variable of interest in order to reduce the impact of selection bias in estimating a treatment effect.

Further, it is common for evaluations to use relatively short time lags ( $<5$ years) post-initiation of regeneration programmes to observe potential changes in specified health outcomes (e.g. Huxley et al., 2004; Petticrew et al., 2008; Stafford et al., 2008), which is arguably too short a period for measurable improvements to become apparent (Lawless, 2013). The use of shorter time lags is often the result of mobility rates in study areas. When these increase, there is a greater likelihood of loss of contact with respondents. Thus, a further major challenge to evaluating area regeneration 
p. 5. Estimating the Impacts of Area Regeneration Programmes in Scotland on Health and Unemployment: a quasi-experimental approach

programmes pertains to the availability of appropriate longitudinal data that can (1) enable the detection of change over time at the small-area level, (2) can account for the fact that resident populations may change substantially during the period of the regeneration, either naturally or indeed as a consequence of the programme, and (3) can have a large enough sample size to generalise findings to the wider population (McCartney et al., 2017).

These examples give an indication of the myriad of difficulties surrounding the evaluation of the impacts of area regeneration initiatives. The Methods section of this paper outlines how these shortcomings will be addressed with this analysis.

\section{Outcome measures}

Rhodes et al. (2005) have maligned the fact that evaluation work (particularly in the UK) focused more on generating evidence on process measures rather than on outcomes that can be related to the impact of regeneration programmes. Indeed, Ying Ho (1999: 423) stated that in the UK, the approach to evaluating area regeneration programmes has been based on "the ideology of value for money and hence skews towards the 'stocktaking' of programme outputs" rather than focusing on impact(s). Despite emphasising that evidence on process is important and should not be discontinued, Rhodes et al. (2005) argued that this must be done in conjunction with a focus on understanding how programmes impact on outcomes.

A further important debate regarding outcome measures and holistic area regeneration programmes centres on whether these programmes are over ambitious with regard to the number of outcomes on which change is being sought. This can be observed with regard to the SARP programmes which aimed for positive change across 16 core indicators covering population, housing, crime, employment and training, education, health and community engagement. Similarly the NDC programme in England sought change on an average of 26 outcomes across 39 areas (Beatty et al. 2010). With that in mind, Lawless (2006) provides evidence to suggest that despite the NDC programme's significant $£ 2$ billion budget, the level of funding required to actually generate positive change in all outcomes, would far exceed that amount. This therefore calls into serious question whether the SARP programmes which had far less funding available than the NDC programme (total $£ 60$ million) could realistically achieve change across the 16 indicators that were targeted, and raises the wider issue of whether holistic programmes should adopt a more realistic approach, and focus on a smaller range of outcomes (Lawless, 2006). The next section will provide detailed background information on the history and key features of the SARP programmes.

\section{Overview of SARP Programmes}

The SARP approach to area regeneration in Scotland comprised three area-based initiatives that were introduced to Scotland in the 1990s: Priority Partnership Areas (PPA) (1996-1999), Regeneration Programme Areas (RP) (1996-1999) and Social Inclusion Partnerships (SIPS) (1999-2006). In 1996, local authorities, backed by other local partners, were asked to apply to the (pre-devolution) Scottish Office for PPA regeneration funding. The PPA programme was designed to bring together local and central government along with the private sector and other organisations (most notably local health boards) in a comprehensive urban regeneration strategy focused on geographical neighbourhoods, most of which were amongst Scotland's 10 per cent most disadvantaged, containing populations of 5,000-30,000 people. Of 29 bids 
p. 6. Estimating the Impacts of Area Regeneration Programmes in Scotland on Health and Unemployment: a quasi-experimental approach

received for funding, 17 were unsuccessful. Thus 12 areas were successful in attaining PPA designation.

Shortly thereafter, however, nine of the 17 areas that were unsuccessful in their bids for PPA funding were awarded compensatory 'Regeneration Programme' (RP) funding by the Scottish Office following heavy criticism of the original PPA bidding process (Taylor et al., 1999). RP area programmes differed from PPAs only in that their funding was originally designed to last for five years as opposed to 10 years for the PPA initiative. Therefore, from 1996, a comprehensive physical, social and economic area regeneration strategy commenced in 21 of Scotland's most disadvantaged areas (see Table 1).

Table 1: Designated PPAs and RPs in Scotland 1996

\begin{tabular}{|l|l|}
\hline Designated PPAs in Scotland (1996) $\mathrm{n}=12$ & Designated RPs in Scotland (1996) $\mathrm{n}=\mathbf{9}$ \\
\hline Torry (Aberdeen) & Cambuslang \\
\hline Craigmillar (Edinburgh) & Whitfield (Dundee) \\
\hline Kirkton and Mid Craigie (Dundee) & Levern Valley \\
\hline Easterhouse (Glasgow) & Leith \& Prestonfield (Edinburgh) \\
\hline Edinburgh North & Falkirk \\
\hline Glasgow East & Fife (various areas) \\
\hline Glasgow North & North Ayrshire \\
\hline Inverclyde & North Lanarkshire \\
\hline Motherwell & Raploch (Stirling) \\
\hline Renfrewshire & \\
\hline South Ayrshire & \\
\hline West Dunbartonshire & \\
\hline
\end{tabular}

Source: Taylor (2002)

The 21 PPA and RP areas were rebranded in 1997 as 'Social Inclusion Partnerships' (SIPs) by the newly elected New Labour Government, crucially without any revision of boundaries (Taylor, 2002). The transition commenced formally in April 1999 with both former PPA and RP areas given designated SIP funding until 2006. The total funding for SIPs in $1999 / 2000$ was $£ 46$ million rising to $£ 60$ million in $2003 / 2004$ (Taylor, 2002). The SIPs initiative had broadly the same aims as the PPA and RP programmes in applying a comprehensive partner-led approach focusing on social, economic and physical renewal of disadvantaged areas (Taylor et al., 2002).

In addition to the 21 PPA and RP areas, 27 new SIPs were announced, 13 of which were area-based and 14 were thematic. The thematic programmes predominantly focused on tackling the social exclusion of young people. However other interventions such as working with marginalised black and ethnic minority groups and preventing atrisk women from entering prostitution were also included. The distinction between the two streams pertained to the fact that area-based SIPs were concerned with issues at the neighbourhood level whilst thematic SIPs focused on issues affecting particular excluded groups and brought together a wider range of partners than those involved in area-based programmes. 
p. 7. Estimating the Impacts of Area Regeneration Programmes in Scotland on Health and Unemployment: a quasi-experimental approach

Given that the SIP programme operated within the original boundaries of the PPA and RP programmes and addressed the same issues, this study focused on the 21 SIP areas that originally had PPA and RP designation from 1996 to maximise the time frame within which the potential impacts on health and unemployment were assessed. Thus, the 13 areas mentioned above that were not previously subject to either PPA or RP phases of the SARP programmes were excluded from the analysis to ensure that they would not be considered as comparator areas. In addition, the 14 thematic SIP projects were not included as they were not strictly area-based. Here the programmes are referred to as Scottish Area Regeneration Partnership Areas (SARPs) to reflect this study's focus on all three branches of this approach to area regeneration from their inception in 1996. The timeline of SARP programme is shown in Figure 1.

Figure 1: SARP programme timeline

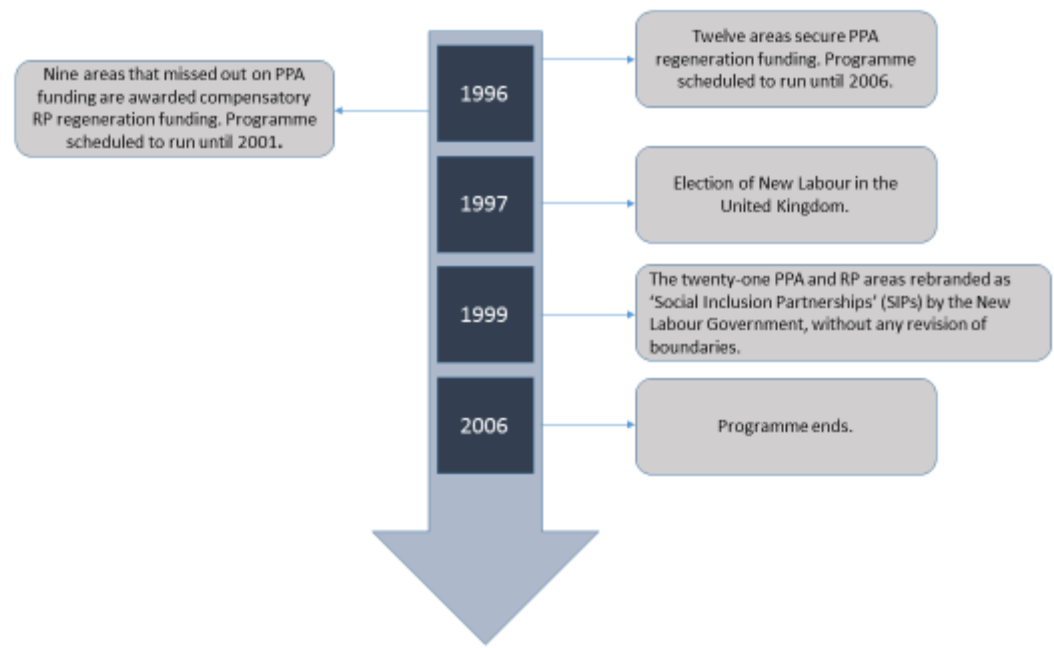

\section{Methods}

\section{Data}

This study used data from the Scottish Longitudinal Study (SLS), a 5.3 per cent sample (around 270,000 individuals) of the Scottish population. The dataset includes a range of routinely collected information including 1991 and 2001 census data, and vital events (births, deaths, marriages) data (Boyle et al., 2008). In addition, health data from NHS Scotland was linked to individual records under strict confidentiality rules. A key advantage of using the SLS is that it enables one to follow individuals through time to determine how regeneration influences those who have experienced the process.

\section{Identifying regeneration area boundaries}

Between 1991 and 2001, census boundaries changed in Scotland making it difficult to compare health trends for small areas. To combat this Exeter et al's (2005) Consistent Areas Through Time (CATTs) system was employed. CATTs are aggregates of the smallest units of census geography in Scotland. In 1991 and 2001 these were called census Output Areas (OAs). The construction of CATTs was conducted to ensure consistent small area comparison through the 1981, 1991, and 2001 Scottish censuses to facilitate reliable analysis of varying demographic, social and economic circumstances at the local level over time (see Exeter et al., 2005 for a full description). 
p. 8. Estimating the Impacts of Area Regeneration Programmes in Scotland on Health and Unemployment: a quasi-experimental approach

Boundary data for the regeneration areas in the form of postcodes were obtained from the Scottish Government. This dataset was linked to census Output Areas using ArcGIS. When the boundaries of the regeneration areas were established at OA level, these were then linked to the CATTs system (again using ArcGIS) so that a list of CATTs defined as PPAs and RPs in 1996 was generated.

Of the 10,058 CATT areas in Scotland the linkage of PPA/RP boundary data to CATTs identified 1,384 CATTs as regeneration areas. However, 21 were removed because they were too large and encroaching into rural areas that had not been subject to regeneration; and a further 18 were dropped because they were found to be in the least deprived of deprivation quintiles. This left 1,345 regenerated CATTs, which are shown in the map below (Figure 2). The map shows that the SARP areas were mostly concentrated in the Central Belt of Scotland. Given that 1,345 CATTs were identified as regeneration areas, this provided 8,674 remaining CATTs for potential selection as comparator areas. 
p. 9. Estimating the Impacts of Area Regeneration Programmes in Scotland on Health and Unemployment: a quasi-experimental approach

Figure 2: Map Showing SARP area boundaries in Scotland

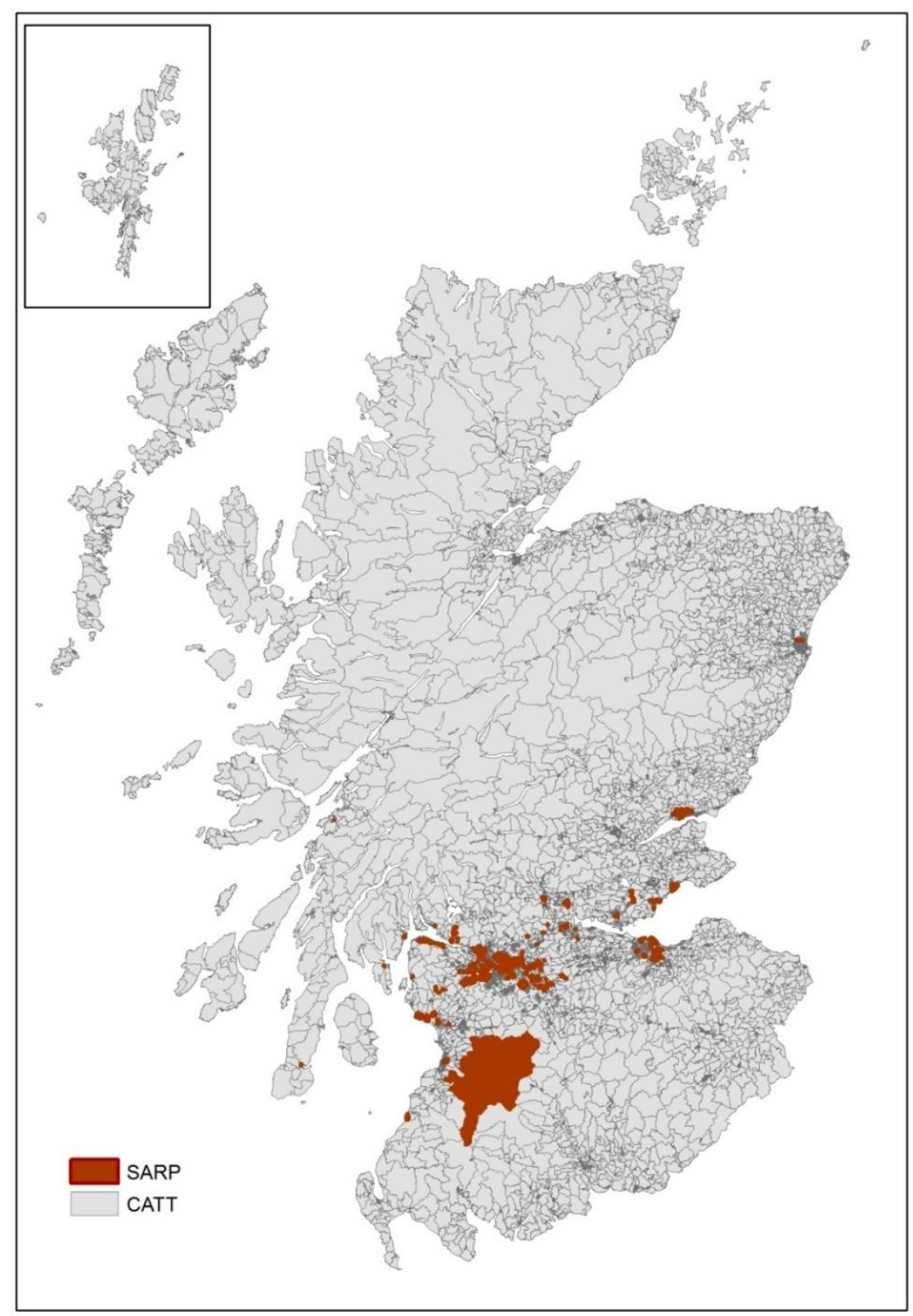

\section{Establishing comparator areas (estimating the counterfactual)}

To provide a measure of the counterfactual the next stage of the analysis involved selecting appropriate comparator CATT areas. Areas - as opposed to individuals - were used as the unit of matching due to the nature of the area-based intervention of interest. The rationale for this approach is built on the work of Leyland (2010: 242) who argued that "if the community is the unit of intervention then it is at the community and not the individual level that balance must be achieved". This process was carried out using propensity score matching (PSM). Propensity scoring involves using logistic regression to estimate the likelihood of being exposed to an intervention given a 
p. 10. Estimating the Impacts of Area Regeneration Programmes in Scotland on Health and Unemployment: a quasi-experimental approach

specified set of co-variates and can be used to match exposed with unexposed individuals or areas. A fuller description of the process can be found elsewhere (see Luellen et al., 2005; Barth et al., 2008).

The process used to apply the PSM technique was firstly to extract thirty-nine 1991 UK Census variables (see Supplementary File A) from CASWEB, a resource based at the University of Manchester that allows the downloading of aggregate UK census statistics and digital boundary data (http://casweb.mimas.ac.uk/). The PSMATCH2 function in STATA 10 was used for the PSM procedure (Leuven and Sianesi, 2003) to identify places that matched the characteristics of the regeneration areas. The areas that received SARP regeneration were multiple disadvantaged areas that were chosen for funding following a bidding process. There were other similarly disadvantaged areas in Scotland that were not allocated funding because a bid was either not submitted or bids that were submitted were considered unsuitable, which made it possible to conduct a quasi-experiment. It was therefore important to identify comparator areas that shared similar characteristics to the regeneration areas.

The thirty-nine 1991 census variables allowed matching between SARP and potential comparator areas on a range of area deprivation measures and on the demographic composition of their populations, thus increasing the ability to make accurate comparisons. Comparator areas were created using the 'nearest neighbour' PSM technique with caliper (Austin, 2011). Care was taken to ensure that the comparator areas were not SARP areas, and to the best of our knowledge, had not been included in any other area-based-initiatives in the past. The nearest neighbour matching technique was utilised, which randomly sorts the intervention and potential comparator CATTs. An initial intervention CATT was chosen to find its closest comparator match based on the value of the difference of the logit of the propensity score of the selected intervention area and the comparator under consideration (Coca Peraillon 2006). The closest comparator CATT was then selected as a match. This process (which was then repeated for all the intervention CATTs) ensures that each intervention CATT found a match. A caliper was imposed so that regeneration and comparator CATTs were only matched if the comparator's propensity score was within a certain propensity score radius. Thus, all eligible non-regeneration CATTs within the radius of the propensity score of a regeneration CATT are matched to that regeneration CATT.

It is important to note that the matching procedure also took into account the issue of 'spill-over effects'. Spill-over effects can occur when regeneration activities in one area have an impact on areas close to (but outwith) the area receiving the intervention. Thus, any comparator area affected would confound the analysis as that area will have a chance of its residents having received some benefit from the regeneration programme. Thus, the procedure used here excluded areas geographically contiguous to regeneration areas, in order to ensure that the selected comparators were unlikely to have experienced spill-over effects.

The results from the PSM balancing process can be viewed in Supplementary File B. The following table (Table 2) shows the number of SLS residents in regeneration areas, comparator areas and the rest of Scotland in 1991 and 2001. 
p. 11. Estimating the Impacts of Area Regeneration Programmes in Scotland on Health and Unemployment: a quasi-experimental approach

Table 2: SLS Sample Members by Area

\begin{tabular}{|l|r|r|r|r|}
\hline & \multicolumn{2}{|c|}{1991} & \multicolumn{2}{c|}{2001} \\
\hline & Frequency & $\%$ & Frequency & $\%$ \\
\hline Regeneration Areas & 39,622 & 14.64 & 36,868 & 13.86 \\
\hline Comparator Areas & 28,529 & 10.54 & 25,287 & 9.51 \\
\hline Rest of Scotland & 202,530 & 74.62 & 203,860 & 76.63 \\
\hline
\end{tabular}

\section{Selection of Outcome Variables}

Three outcome variables were employed in the analysis - limiting long term Illness (LLTI), hospital admissions and unemployment. Information on two of these variables (LLTI and unemployment) was available directly from the SLS covering the period 19912001, whilst data on hospital admissions were obtained from the Information Services Division (ISD) of NHS Scotland. The latter were subsequently linked to the SLS.

Limiting Long Term IIIness was included as a self-reported measure of morbidity. It is defined as a long-term illness, health problem or disability which limits a person's daily activities or the work that they can do, including problems that are due to old age (Cohen et al., 1995). LLTI was included among the compulsory indicators to be targeted for improvement by the SARP programmes (ODS Consulting, 2006), however, there has been no reliable evidence to date on the impact of the programmes on LLTI.

Unemployment is conceptualised in this analysis as an indicator of poor health (McCartney et al., 2017). Not only does the extant literature on the effects of unemployment indicate a strong association with poor health outcomes (e.g. Dahlgren and Whitehead, 1991; Kearns et al., 2009) but unemployment was also included as a core indicator to be monitored during the SARP programmes. Again, there is a lack of clear evidence on the impact of the programmes on this outcome.

Hospital admissions was included as an outcome variable to provide a clinical measure of morbidity that can be compared with the self-reported LLTI outcome. Hospital admissions refer to any inpatient or day care visit to hospital, excluding maternal examinations. Like self-reported rates of LLTI, hospital admissions have been found to be higher in disadvantaged areas (Daly et al., 2000). Reducing preventable and unscheduled hospital admissions for residents was not an explicitly stated aim of the SARP programmes. Nevertheless, it would be expected that efforts to reduce rates of LLTI would impact to some extent on rates of admissions, given the correlation between the two outcomes. Indeed, Atkinson et al. (2006) cited a report from the United Kingdom Department for the Environment, Transport and the Regions (DETR, 1996) that argued regeneration will have indirect benefits for employment, quality of life, levels of stress and the cost of hospital admissions or medicines.

The major difference between this outcome variable and the other two used in this study (unemployment and LLTI) is that hospital admissions events in the regeneration and comparator areas were analysed using two three-year time periods. The first of these periods (1991-1994) was selected to provide an understanding of hospital admissions prevalence (period prevalence) in these areas before the regeneration programmes commenced in 1996. The second three-year period selected (2001-2004) allows an understanding of hospital admissions prevalence in regeneration and comparator areas when the regeneration partnership programmes were at the half way stage and beyond. This strategy facilitated the assessment of morbidity over five years following the initiation of the SARP programmes (LLTI), whilst the two hospital admissions measures extended the assessment period. This strategy facilitated an 
p. 12. Estimating the Impacts of Area Regeneration Programmes in Scotland on Health and Unemployment: a quasi-experimental approach

objective assessment of morbidity and, importantly, also allowed a measure of the impact of the SARP programmes on health that provides the longest time lag of all outcomes assessed here - a period of eight years following the inception of the programmes.

Table 3 below shows that the SARP and comparator areas were broadly comparable at baseline with regard to the selected outcome variables.

Table 3: Comparison of SARP and Comparator Areas on Outcome Variables at Baseline

\begin{tabular}{|l|l|r|r|r|r|}
\hline \multicolumn{1}{|c|}{ Variable } & Category & \multicolumn{2}{c|}{ SARP Areas } & \multicolumn{2}{c|}{ Comparator Areas } \\
\hline & & \multicolumn{2}{|c|}{1991} & \multicolumn{2}{c|}{1991} \\
\hline \multirow{2}{*}{ LLTI } & & Frequency & $\%$ & Frequency & $\%$ \\
\hline \multirow{2}{*}{ Hospital Admission } & Yes & 4,286 & 15.7 & 2,879 & 16.9 \\
\cline { 2 - 6 } & No & 22,960 & 84.3 & 14,212 & 83.2 \\
\cline { 2 - 6 } & Yes & 7,644 & 28.3 & 4,827 & 28.5 \\
\hline \multirow{2}{*}{ Unemployed } & No & 19,360 & 71.7 & 12,112 & 71.5 \\
\cline { 2 - 6 } & Yes & 2,024 & 16.1 & 1,283 & 16.8 \\
\cline { 2 - 6 } & No & 10,536 & 83.9 & 6,353 & 83.2 \\
\hline
\end{tabular}

\section{Control Variables}

A range of individual-level variables available from the SLS that represented direct or indirect indicators of the determinants of health were chosen as independent variables for the statistical analyses. These variables represent characteristics, such as age, gender and socio-economic circumstances, thought to be important in explaining changes in the outcome variables over the study period. Descriptive statistics for the control variables are summarised in Table 4. The mean age in both SARP and comparator areas is in the mid to late 40s range and broadly similar at both 1991 and 2001. However, the mean age of residents in SARP areas rises slightly over the tenyear period (from 46.3 to 47.8 years) but falls in comparator areas (from 48.6 to 45.7 years). Women are overrepresented in the sample at both time periods and in both SARP and comparator areas. Most residents in the sample were single and in full-time employment, although the percentage of residents in full-time employment fell slightly over the ten- year period in both SARP and comparator areas. In terms of housing, in 1991 most residents in SARP areas rented social housing but by 2001 the majority were homeowners. This pattern is also observed in the comparator areas and is likely to be a result of national-level changes in home ownership initiated by the Right to Buy policy introduced to the UK in the 1980s by the Conservative Government. It should be noted that on some dimensions, the comparator areas appeared to have higher levels of disadvantage at baseline. For example, with regard to housing, more people in SARP areas owned a house relative to comparator areas (38.8 per cent vs 32.5 per cent). In addition, there were more people in comparator areas without access to a car $(52.3$ per cent vs 49.8 per cent in SARP areas). It is important to remember that that the process of gaining SARP designation was via a competitive bidding process and was thus a political decision, rather than one based on data. It is therefore perhaps unsurprising that comparator areas experienced more disadvantage in some dimensions. The allocation of funds via a bidding process favoured areas that were able to muster the necessary resources to do this, whilst areas with less resources were disadvantaged in the process (McCarthy, 2007). 
p. 13. Estimating the Impacts of Area Regeneration Programmes in Scotland on Health and Unemployment: a quasi-experimental approach

Table 4: Summary of control variables included in the research

\begin{tabular}{|c|c|c|c|c|c|c|c|c|c|}
\hline \multirow[t]{3}{*}{ Variable } & \multirow[t]{3}{*}{ Category } & \multicolumn{4}{|l|}{ SARP Areas } & \multicolumn{4}{|c|}{ Comparator Areas } \\
\hline & & \multicolumn{2}{|c|}{1991} & \multicolumn{2}{|c|}{2001} & \multicolumn{2}{|l|}{1991} & \multicolumn{2}{|c|}{2001} \\
\hline & & Frequency & $\%$ & Frequency & $\%$ & Frequency & $\%$ & Frequency & $\%$ \\
\hline \multirow{2}{*}{ Sex } & Male (reference) & 12,898 & 47.3 & 12,084 & 47.2 & 8,115 & 47.5 & 7,029 & 46.9 \\
\hline & Female & 14,348 & 52.6 & 13,515 & 52.8 & 8,976 & 52.5 & 46.89 & 53.1 \\
\hline \multirow{2}{*}{ Marital Status } & Widowed & 1,481 & 5.4 & 1,776 & 7.0 & 972 & 5.7 & 1,109 & 7.5 \\
\hline & Divorced & 2,110 & 7.7 & 1,723 & 6.8 & 1,330 & 7.8 & 1,145 & 7.7 \\
\hline \multirow{4}{*}{ Social Class } & Professional (reference) & 331 & 1.2 & 474 & 1.8 & 155 & 0.9 & 221 & 1.5 \\
\hline & Managerial & 2,715 & 9.9 & 3,483 & 13.6 & 1,308 & 7.6 & 1,645 & 11.0 \\
\hline & Unskilled & 1,603 & 5.9 & 1,528 & 5.9 & 1,082 & 6.3 & 1,090 & 7.3 \\
\hline & Never worked & 12,459 & 45.7 & 9,426 & 36.8 & 7,891 & 46.8 & 5,692 & 38.0 \\
\hline \multirow{5}{*}{ Economic Status } & In full-time employment (reference) & 7,877 & 28.9 & 6,918 & 27.0 & 4,679 & 27.4 & 3,791 & 25.3 \\
\hline & In part-time employment & 2,031 & 7.4 & 1,872 & 7.3 & 1,330 & 7.8 & 1,087 & 7.2 \\
\hline & Self-employed & 628 & 2.3 & 675 & 2.6 & 344 & 2.0 & 337 & 2.2 \\
\hline & Unemployed & 2,024 & 7.4 & 941 & 3.7 & 1,283 & 7.5 & 552 & 3.7 \\
\hline & Student & 6,483 & 23.8 & 6,456 & 25.2 & 4,034 & 23.6 & 3,636 & 24.2 \\
\hline
\end{tabular}

(c) 2019 The Author

Journal Compilation @ 2019 PPP

People, Place and Policy (2019): 13/1, pp. 1-28 
p. 14. Estimating the Impacts of Area Regeneration Programmes in Scotland on Health and Unemployment: a quasi-experimental approach

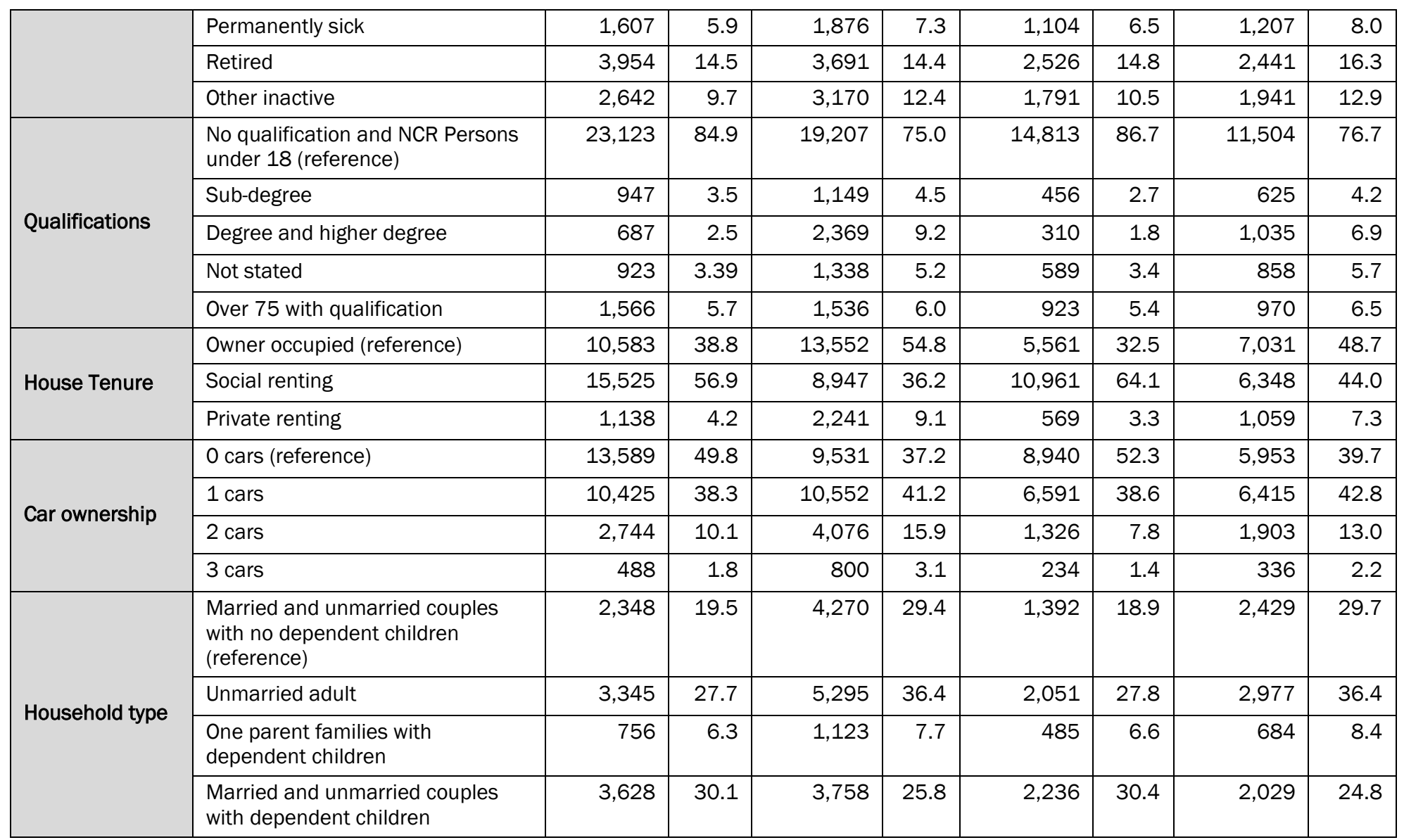


p. 15. Estimating the Impacts of Area Regeneration Programmes in Scotland on Health and Unemployment: a quasi-experimental approach

\section{Difference in Differences (DiD)}

The aim of the Difference in Differences (DiD) method is to measure the average impact of a policy programme on a specific outcome (Gutiérrez-Romero and Noble, 2008). The underlying approach centres on the assumption that in the absence of a programme, a treated group would experience the same changes as a comparison group. The method therefore estimates average changes in outcome variables in intervention and comparator groups before and after the introduction of the SARP programmes to estimate the programme's impact. DiD focuses not on the absolute differences between intervention and comparator groups but on the differences in changes over time between these groups (or difference in differences) and thus removes potential unobserved confounding in differences between the two groups that are fixed over time (Farrar et al., 2009).

The DiD approach takes the changes occurring both in the intervention and comparator groups into account. In this case, we expect that, even without the regeneration programme, there would be changes in the outcomes for residents in both intervention and comparator areas between 1991 and 2001, reflecting nationallevel changes. Thus, the DiD analyses aim to identify whether the SARP programmes had any net effects on residents in the intervention group.

The DiD analysis was undertaken using conditional fixed-effects logistic regression to model the net impact of the SARP programmes on Limiting Long Term Illness, Hospital Admissions and Unemployment. Estimating DiD is commonly undertaken using a regression model, in which variables such as marital status and social class can be used to control for confounding effects. Fixed effects regression modelling differs from regular logistic regression in the sense that the data are grouped as each individual has more than one observation over time and, unlike logistic regression, the likelihood is calculated relative to each group (Gutiérrez-Romero and Noble 2008). The regression equation can be represented in the following form:

$$
\operatorname{logit}\left(\Delta Y_{i t)}=\beta_{0}+\beta_{1} T_{i}+\beta_{2} P_{t}+\beta_{3} T_{i} * P_{t}+\beta_{4} X_{i t}+\varepsilon_{i t}\right.
$$

Where $Y_{i t}$ is the outcome investigated (probability of limiting long term illness, hospital admissions or unemployment) for individual $i$ in time $t . T_{i}$ is a dummy variable indicating living in the SARP area, $P_{t}$ is a dummy variable showing the time after the SARP programmes started, in this case 2001, or the second period for the hospital admissions outcome; $T_{i} * P_{t}$ is the interaction term between the SARP area indicator and the post-intervention indicator. The key parameter $\beta_{3}$ provides the estimate for the effect of SARP intervention on the outcome variable $Y_{i t}$. The control variables are represented by $X_{i t}$.The DiD effects were estimated in STATA 12.0 to investigate the effect of the SARP programmes on the outcomes of interest.

\section{Results}

Table 5 below presents the results of the DiD analysis for each of the three outcomes. It should be noted that different samples were used for each outcome. The modelling for unemployment and LLTI used a sample of SLS members from the UK census living in SARP and comparator areas (aged 18-64 in the case of the unemployment modelling), whilst the hospital admissions modelling used a sample from NHS Information Services Division (ISD) data linked to the SLS. 
p. 16. Estimating the Impacts of Area Regeneration Programmes in Scotland on Health and Unemployment: a quasi-experimental approach

Several conclusions can be arrived at regarding the factors that affect the likelihood of being unemployed, having an LLTI or being admitted to hospital in the sample under study. For example, the results demonstrate that the characteristics most likely to increase the odds of experiencing unemployment are renting one's accommodation privately, being a lone parent and not owning a car.

The results for the LLTI outcome demonstrate that economic status plays an important role with regard to the likelihood of experiencing LLTI or being admitted to hospital for people living in disadvantaged areas in Scotland. The characteristics most likely to increase the odds of experiencing LLTI are being retired and living as part of a couple with no children. Further, those residents most likely to be admitted to hospital are divorced and retired individuals.

Looking at the coefficients indicating the effect of SARP programmes, we can see that people in the SARP areas were less likely to be unemployed than those in nonSARP comparator areas (Odds ratio (OR): 0.94, 95 per cent confidence interval $(\mathrm{Cl})$ 0.64-1.40). Similarly, people in the SARP areas were less likely to be admitted to hospital (OR: 0.95, 95 per cent $\mathrm{Cl}$ 0.85-1.06). In contrast, people in the SARP areas were more likely to report LLTI (OR: 1.14, 95 per cent $\mathrm{Cl}$ 0.87-1.49). However, none of these effects are statistically significant as the 95 per cent confidence interval includes the value of one.

In summary, the DiD modelling demonstrates that the SARP programmes had no statistically significant net positive (or negative) impact on the likelihood of unemployment or morbidity for regeneration area residents relative to residents in comparator areas net of all other variables. These results do not reflect positively on the SARP strategy to tackle unemployment and indeed suggest that the SARP programmes were unable to improve the employment prospects of SARP residents or improve their morbidity levels. 
p. 17. Estimating the Impacts of Area Regeneration Programmes in Scotland on Health and Unemployment: a quasi-experimental approach

Table 5: Fixed effect regression models predicting the net impact of SARP on Unemployment, LLTI and Hospital Admissions between 1991 and 2001

\begin{tabular}{|c|c|c|c|c|c|c|c|}
\hline & & \multicolumn{2}{|c|}{ Unemployment } & \multicolumn{2}{|c|}{ LLTI } & \multicolumn{2}{|c|}{ Hospital Admissions } \\
\hline & & \multicolumn{2}{|c|}{$n=1262$} & \multicolumn{2}{|l|}{$n=7622$} & \multicolumn{2}{|l|}{$n=13378$} \\
\hline & & OR & $95 \% \mathrm{Cl}$ & OR & $95 \% \mathrm{Cl}$ & OR & $95 \% \mathrm{Cl}$ \\
\hline \multirow{2}{*}{ Time } & Pre-regeneration (year 1991) (reference) & 1 & & 1 & & 1 & \\
\hline & Post regeneration (Year 2001)a & $0.68 *$ & $0.49,0.96$ & $6.83 * * *$ & $5.31,8.80$ & $1.28 * * *$ & $1.15,1.41$ \\
\hline \multirow{2}{*}{ Area } & Comparison area (reference) & 1 & & 1 & & 1 & \\
\hline & SARP area & 1.57 & $0.68,3.64$ & 0.54 & $0.28,1.31$ & $1.39 * *$ & $1.08,1.79$ \\
\hline Control Variables & Category & & & & & & \\
\hline \multirow{4}{*}{ Marital Status } & Single (reference) & 1 & & 1 & & 1 & \\
\hline & Married & 0.51 & $0.24,1.07$ & 1.81 & $0.71,4.61$ & 1.25 & $0.94,1.66$ \\
\hline & Widowed & 0.78 & $0.32,1.91$ & 2.00 & $0.71,5.68$ & 1.11 & $0.78,1.58$ \\
\hline & Divorced & 7.94 & $0.99,63.50$ & 2.44 & $0.89,6.70$ & $1.80 * *$ & $1.26,2.57$ \\
\hline \multirow{5}{*}{ Economic Status } & In part-time employment & $\mathrm{n} / \mathrm{a}$ & & 1.43 & $0.87,2.34$ & 1.13 & $0.96,1.33$ \\
\hline & Self-employed & $\mathrm{n} / \mathrm{a}$ & & 1.66 & $0.66,4.20$ & 0.87 & $0.63,1.19$ \\
\hline & Unemployed & $\mathrm{n} / \mathrm{a}$ & & $3.48 * * *$ & $2.11,5.73$ & 0.93 & $0.77,1.11$ \\
\hline & Student & $\mathrm{n} / \mathrm{a}$ & & 2.51 & $0.99,6.39$ & 1.20 & $0.86,1.77$ \\
\hline & Permanently sick & $\mathrm{n} / \mathrm{a}$ & & $1151.33 * * *$ & $\begin{array}{l}431.12 \\
3074.66\end{array}$ & $1.36 * * *$ & $1.14,1.61$ \\
\hline
\end{tabular}

(c) 2019 The Author

People, Place and Policy (2019): 13/1, pp. 1-28 
p. 18. Estimating the Impacts of Area Regeneration Programmes in Scotland on Health and Unemployment: a quasi-experimental approach

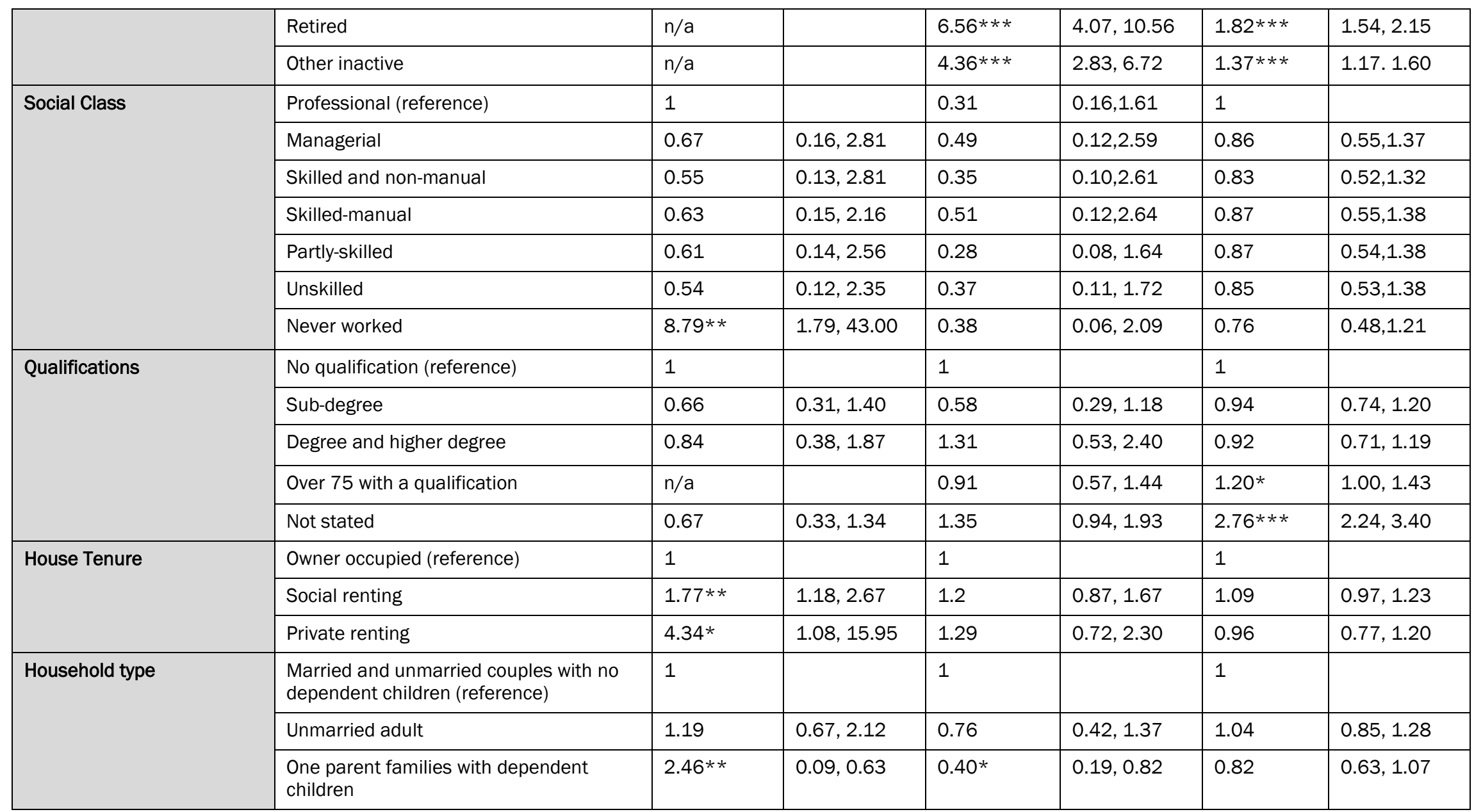


p. 19. Estimating the Impacts of Area Regeneration Programmes in Scotland on Health and Unemployment: a quasi-experimental approach

\begin{tabular}{|c|c|c|c|c|c|c|c|}
\hline & $\begin{array}{l}\text { Married and unmarried couples with no } \\
\text { dependent children }\end{array}$ & $0.63 *$ & $0.41,0.96$ & $0.57 *$ & $0.37,0.88$ & 0.92 & $0.59,1.43$ \\
\hline \multirow[t]{5}{*}{ Car ownership } & 0 cars (reference) & 1 & & 1 & & 1 & \\
\hline & $1 \mathrm{car}$ & $0.48 * * *$ & $0.34,0.72$ & 0.64 & $0.47,0.87$ & 0.9 & $0.81,1.02$ \\
\hline & 2 cars & $0.38 * * *$ & $0.21,0.64$ & 0.72 & $0.43,1.19$ & 0.87 & $0.73,1.03$ \\
\hline & 3 cars & $0.41 *$ & $0.16,0.85$ & 0.55 & $0.23,1.27$ & 0.81 & $0.61,1.07$ \\
\hline & Log Likelihood & \multicolumn{2}{|c|}{-348.73088} & \multicolumn{2}{|c|}{-807.09691} & \multicolumn{2}{|c|}{-807.09691} \\
\hline
\end{tabular}

a 2001-2004 for hospital admissions

$* \mathrm{P}<0.05, * * \mathrm{p}<0.01, * * * \mathrm{p}<0.001$ 
p. 20. Estimating the Impacts of Area Regeneration Programmes in Scotland on Health and Unemployment: a quasi-experimental approach

\section{Discussion}

The objective of this study was to evaluate the impact that the Scottish Area Regeneration Partnership (SARP) programmes had on health and unemployment in Scotland using a quasi-experimental approach. The central research question asked if living in SARP areas had a positive or negative impact on the likelihood of residents being unemployed or suffering morbidity compared with residents living in matched comparator areas that did not receive the programme. The study found no impact of the SARP programmes (positive or negative) for regeneration area residents compared with those living in comparator areas with regard to those outcomes. The following discussion will explore the reasons that might underlie this central finding.

\section{Unemployment}

Firstly, in terms of how the findings fit with other evidence in this field, the picture is mixed. With the unemployment modelling in mind, McCartney et al's (2017) review found that very few studies have been undertaken in this area and that the studies that have been undertaken have tended to be of low quality. One relevant high quality study (Gutiérrez-Romero and Noble, 2008) however used a quasi-experimental approach to investigate the impact of the NDC programme on unemployment and found that the programme did not increase the likelihood of employment for those who claimed unemployment benefits before the programme began. The results here accord with this finding. However, the study also found that the programme increased the chances of finding employment for those who were claiming incapacity benefit (or those in full time training/education) before the programme began.

Economic (and social) exclusion was identified as a key concern of the SARP programmes, particularly in the SIP phase, where a clear commitment was made to prevent younger people and others such as the non-employed (a term which includes both the unemployed and the economically inactive) from becoming excluded from the economic and social mainstream (Taylor, 2002). These issues were tackled in the form of 'supply-side' measures such as education and vocational training programmes, as well as employment advice. In their attempt to address the issue of economic inactivity, the SARP programmes emphasised the benefits of being in-work to encourage and enable people to move from non-employment into work (Carley, 2002).

This focus on supply-side measures to address economic activity has been criticised for de-emphasising 'demand-side' issues, which centre on job creation. It has been argued that job creation should be the primary focus of area-based regeneration as supply-side measures alone may not be sufficient to deal with spatial concentrations of unemployment when an inadequate demand for labour and a lack of jobs exist in disadvantaged areas (Green and Owen, 1998; Turok and Edge, 1999). Nevertheless, when job creation has been attempted as part of Scottish area regeneration in the past - for example, in the late 1970s through the Glasgow Eastern Area Renewal (GEAR) project (which attempted to create jobs through facilitating improvements to the environment and infrastructure to attract and retain industry (Turok, 2004) - it has been found to be unsuccessful due to inadequate levels of funding (Webster, 2002). Thus, since the late 1980 s, job creation has been seen to be out with the capabilities and remit of area regeneration projects, rather the focus has been on training and job placements to tackle unemployment (Webster, 2002).

An emphasis on training and job placements in regards to unemployment strategy reflects the view that economic development is difficult to achieve within more 
p. 21. Estimating the Impacts of Area Regeneration Programmes in Scotland on Health and Unemployment: a quasi-experimental approach

deprived areas but simpler at the wider regional level (Turok, 2004). The location or even total number of jobs, therefore, appears to matter less than the ability of the unemployed to compete in the wider labour market (Webster, 1994; 2002). The change of strategy from job creation to more supply-side aspects such as training and job placement was seen as more cost effective and implied that the causes of unemployment were due to deficiencies in personal skills rather than labour demand shortages, despite increasing job shortages in urban areas (Turok, 2004). The findings of the present study did not indicate that the supply-side approach adopted by the SARP initiative to combat unemployment had been successful, and thus supports the likes of Webster (2000) and Turok (2004) who argue that the key to combating unemployment is to concentrate efforts on the demand-side of the employment equation through economic regeneration in order to encourage investment and economic development in disadvantaged areas and, ultimately, job creation.

A focus on supply issues does appear to be an essential part of an effective regeneration strategy as, regardless of the number of jobs available, if unemployed individuals in disadvantaged areas do not have the qualifications and skills to make them competitive when applying for a job, then they will remain unemployed. Nevertheless, as Webster (2000) points out, all the groups targeted by initiatives like the SARP programmes (such as youth unemployed, long-term unemployed, long-term sick and lone parents) are concentrated in the same areas of high unemployment and cannot all get back into work unless the supply of jobs in the local area is increased. These observations underline the tensions between achieving a workable balance between supply and demand approaches to tackle unemployment in disadvantaged areas.

\section{Morbidity}

Morbidity was investigated in this analysis using both a subjective measure (LLTI) and an objective measure (hospital admissions) of poor health. The LLTI variable allowed five years' post initiation of the programmes to investigate a potential regeneration effect, whereas the hospital admissions variable had eight years post initiation of the programmes to investigate an effect. Based on the results of the analyses, the overarching findings of the morbidity modelling indicate that the SARP programmes appear to have had no impact (positive or negative) on an individual's likelihood of experiencing morbidity.

As programmes such as SARP and the New Deal for Communities (NDC) attempted to decrease rates of morbidity (specifically targeting $\mathrm{LLTI}$ ) there is a strong justification for the selection of these outcomes. In addition, there is also a precedent in the literature for assessing how regeneration programmes impact on the morbidity outcomes included in this study. Indeed, a previous evaluation of the NDC programmes by Stafford et al. (2008) included LLTI as an outcome measure, and also found no improvement. Similarly, two other studies undertaken on the NDC programme in England, (Walthery et al., 2015; Stafford et al., 2014) found that self-rated health did not improve relative to that in comparator areas. However, with regard to objective measures such as hospital admissions, McCartney et al's (2017) recent review found that three studies had reported positive impacts (Jackson et al., 2011; Heyman et al., 2011; Maidment et al., 2014), which diverge from the findings here. However, the programmes in question in these three studies focused on housing-led regeneration and not holistic regeneration. 
p. 22. Estimating the Impacts of Area Regeneration Programmes in Scotland on Health and Unemployment: a quasi-experimental approach

\section{Challenges associated with selection of morbidity measures}

The absence of an observable regeneration impact may be due to the programme simply having no effect, or perhaps that the outcome measures selected may be unable to discern any change (Cotterill et al., 2008). In this case there are limitations associated with the use of the morbidity outcome measures, which are both diverse in scope. Payne and Saul (2000) for example, found that conditions such as angina, depression, musculoskeletal disorders, stroke and asthma are associated with reporting LLTI (after adjusting for age differences). Some of these conditions (e.g. angina, as a symptom of coronary heart disease) are unlikely to be impacted within a five-year time frame. With regard to hospital admissions, again many conditions will be included under this general measure. Admissions associated with diseases such as cancer, for example, will be unlikely to decrease within the eight-year time frame available here. However, other admissions for issues such as unintentional accidents may potentially be reduced in the short-term through housing and environmental improvements (Cotterill et al., 2008; Egan et al., 2015). However, the reach of area regeneration programmes are generally low and in regeneration areas there will be significant numbers of people who will not be exposed to programme initiatives. For example Foden et al. (2010) distinguish between those who directly benefit from programme initiatives (beneficiaries) and those who do not (non-beneficiaries), stating that in 200421 per cent of people living in NDC areas had not heard of the initiatives, despite having been in place for six years by that point. Positive change will therefore likely take time to occur at the population level, particularly on outcomes (such as hospital admissions and LLTI) which are secondary impacts of holistic regeneration programmes (CLG, 2008). Thus, despite the fact that regeneration programmes such as SARP focused on encouraging healthy eating, improvements to the built environment and promotion of physical activity, it may take 10 or even 20 years for change to be noted if such interventions can successfully modify disease aetiology and disease progression in relation to conditions such as (for example) coronary heart disease (Cotterill et al., 2008).

Other researchers however (e.g. Ruijsbroek et al., 2017) argue that time-lags of five or six years can be adequate to observe positive results from regeneration efforts regarding other health outcomes. For example, symptom reduction of conditions such as asthma and depression can feasibly be impacted within shorter time frames. Egan et al. (2015) found that asthma symptoms may improve rapidly following a move out of poor quality housing. In addition, other studies (e.g. Whitley and Prince, 2006) have found evidence to suggest that area regeneration programmes may decrease depression symptoms, particularly through community safety initiatives that in particular, tackle anti-social behaviour. Initiatives that were found by Whitely and Prince (2006) to be effective in this regard included strategically located CCTV cameras, new security entry systems in blocks of flats and re-design of open spaces, which can all be implemented in a short time frame following the commencement of a regeneration programme.

Thus, it would seem that the morbidity measures used in this analysis may be less sensitive to change over shorter time periods than those mentioned above. Nevertheless, whilst there are limitations associated with the morbidity outcome measures used here, data available to undertake an analysis of the health impacts of the SARP programmes is scarce, and the SLS data presented a unique opportunity to conduct a rigorous quasi-experimental evaluation of the programmes. One key general factor however regarding the absence of a regeneration effect noted here, is simply the length of time it takes for projects to get up and running following the process of an area receiving long-term regeneration status. Indeed, with regard to the NDC 
p. 23. Estimating the Impacts of Area Regeneration Programmes in Scotland on Health and Unemployment: a quasi-experimental approach

programme, Lawless et al. (2010) explains how the early years of large holistic programmes often involve the setting up of operational processes regarding finance and project management. This is likely to have also been the case with the SARP programmes and thus, the time-lag value that the SLS data provides to observe regeneration effects may be over-estimated, particularly in the case of the LLTI and unemployment outcomes whereby the data time period extends only to 2001.

\section{Community engagement}

A further point that should be considered with regard to the results is community engagement. This issue has been investigated in qualitative studies (e.g. Carlisle, 2010) that have strongly emphasised the need for community engagement strategies embedded within the area regeneration initiative. Previous research has suggested (e.g. Mathers et al., 2008; Gosling, 2008; Popay et al., 2015) that, without effective community engagement, residents feel disempowered and alienated and thus less likely to benefit from regeneration initiatives. It is therefore key that communities have an active involvement in regeneration programmes so that initiatives actively attempt to address issues that are important to the community.

\section{Conclusion}

Evaluating area regeneration programmes is a challenging process and the programmes themselves are complex interventions serving heterogeneous populations. This study aimed to ascertain if the SARP programmes improved residents' health and employment outcomes. This was undertaken by exploiting opportunities offered by quasi-experimental approaches to evaluation. In attempting this, certain challenges were faced, as outlined in the second section of this paper. The study addressed the challenges to undertaking a rigorous quasi-experimental analysis by employing data from the SLS and applying PSM and DID to tackling some of the key limitations of previous studies. This allowed a measure of the counterfactual to be provided, providing an understanding of what would have happened in the absence of the SARP initiatives. Furthermore, many previous evaluations have often not been able to account for programme effects beyond national or regional trends. Here, the Difference in Differences (DiD) estimator which accounts for national trends was employed to identify whether the SARP programme has any net effects on unemployment and health for residents in regenerated areas over the study period. The study therefore designed a robust evaluation making use of the best available data for the purpose of assessing the impacts of area regeneration on health by using quantitative techniques that have seldom been used in this context previously.

The implications of the findings of this study raise the question of whether pursuing area-based regeneration is a worthwhile endeavour. As is stated earlier in this paper, it is important to consider the scale, reach, and level of resourcing available to programmes and ask the question of whether there is a need for holistic programmes to be less ambitious with regard to seeking positive change across such an array of domains. Lawless (2006) argued that the NDC programme's $£ 2$ billion budget (equating to the distribution of roughly $£ 50$ million to each of the programme's 39 areas) was likely to be insufficient to promote they type of change being sought on multiple outcomes in 39 target areas. The SARP programme had similar ambitions to effect change across multiple areas but received much less funding relatively, $£ 60$ million across 21 areas (containing between 5,000 and 30,000 residents), equating to just under $£ 3$ million per area. One may suspect therefore, that even if longer-term data become available, positive change across the indicators that SARP programmes 
p. 24. Estimating the Impacts of Area Regeneration Programmes in Scotland on Health and Unemployment: a quasi-experimental approach

were attempting to impact (of which LLTI and unemployment were included) may be unlikely. Thus, we concur with Lawless's (2013) assertion that if Governments decide to pursue area regeneration programmes, ambitious plans regarding what might plausibly be achieved should be caveated to be more realistic, and perhaps target a narrower range of outcomes.

\section{Acknowledgements}

The help provided by staff of the Longitudinal Studies Centre - Scotland (LSCS) is acknowledged. The LSCS is supported by the ESRC/JISC, the Scottish Funding Council, the Chief Scientist's Office and the Scottish Executive. The authors alone are responsible for the interpretation of the data. Census output is Crown copyright and is reproduced with the permission of the Controller of HMSO and the Queen's Printer for Scotland.

*Correspondence address: Daryll Archibald, Department of Public Health, School of Psychology and Public Health, College of Science, Health and Engineering, La Trobe University, Melbourne, Vic, Australia, 3086. Email: D.archibald@latrobe.edu.au

\section{References}

Archibald, D. (2014) Does area regeneration improve residents' health and well-being? Unpublished PhD Thesis. University of St-Andrews.

Atkinson, R., Thomson, H., Kearns, A. and Petticrew, M. (2006) Giving urban policy its 'medical': assessing the place of health in area-based regeneration. Policy and Politics, 34, 1, 5-26.

Austin, P.C. (2011) Optimal caliper widths for propensity-score matching when estimating differences in means and differences in proportions in observational studies. Pharmaceutical Statistics, Mar-Apr, 10, 2, 150-61.

Barth, R., Guo, S. and McRae, J.S. (2008) Propensity Score Matching Strategies for Evaluating the Success of Child and Family Service Programs. Research on Social Work Practice, 18, 212.

Boyle, P.J., Feijten, P., Feng, Z., Hattersley, L., Huang, Z., Nolan, J. and Raab, G. (2008) Cohort Profile: The Scottish Longitudinal Study (SLS). International Journal of Epidemiology, 1-8.

Carley, M. (2002) Community Regeneration and Neighbourhood Renewal: a review of the evidence. Communities Scotland.

Carlisle, S. (2010) Tackling health inequalities and social exclusion through partnership and community engagement? A reality check for policy and practice aspirations from a Social Inclusion Partnership in Scotland. Critical Public Health, 20, 1, 117 127.

Clark, W, A.V. (2008) Reexamining the Moving to Opportunity Study and its Contribution to Changing the Distribution of Poverty and Ethnic Concentration. Demography, 45, 3, 515-535.

CLG (2008) New Deal for Communities: a synthesis of new programme wide evidence: 2006_07 - Research Report 39. London: Department for Communities and Local Government.

Coca Peraillon, M. (2006) Matching with Propensity Scores to Reduce Bias in Observational Studies. Adheris Inc., Burlington, MA.

Cohen, G., Forbes, J. and Garraway, M. (1995) Interpreting self-reporting limiting long term illness. BMJ, 1995, 311, 722-4. 
p. 25. Estimating the Impacts of Area Regeneration Programmes in Scotland on Health and Unemployment: a quasi-experimental approach

Cole, I., Lawless, P., Manning, J. and Wilson, I. (2007) The moving Escalator? Patterns of Residential Mobility in New Deal for Community Areas. Sheffield: CRESR, Sheffield Hallam University.

Cotterill, S., Parry, J., Richardson, M. and Mathers, J. (2008) Quasi-Experimental Evaluation of the Health Impacts of the New Deal for Communities Urban Regeneration Scheme. Critical Public Health, 18, 3, 311-332.

Curtis, S., Cave, B. and Coutts, A. (2002) Is urban regeneration good for health? Perceptions and theories of the health impacts of urban change. Environment and Planning C: Government and Policy, 20, 517-534.

Dahlgren, G. and Whitehead, M. (1991) Policies and strategies to promote social equity in health. Stockholm: Institute for Future Studies.

Daly, E., Mason, A. and Goldacre, M. (2000) Using admission rates as a health outcome indicator: Literature review. Report to the Department of Health.

DETR (Department of the Environment, Transport and the Regions) (1996) Health and regeneration. London: DETR

Des Jarlais, D.C., Lyles, C. and Crepaz, N. (2004) Improving the Reporting Quality of Nonrandomized Evaluations of Behavioral and Public Health Interventions: The TREND Statement. American Journal of Public Health, 94, 3.

Egan, M., Lawson, L., Kearns, A., Conway, E. and Neary, J. (2015) Neighbourhood demolition, relocation and health. A qualitative longitudinal study of housing-led urban regeneration in Glasgow, UK. Health and Place, 33, 101-108. DOI: 10.1016/j.healthplace.2015.02.006

Exeter, D.J., Boyle, P., Feng, Z., Flowerdew, R. and Schierloh, N. (2005) The Creation of Consistent Areas Through Time' (CATTs) in Scotland (1981-2001). Population Trends, 119, 28-36.

Farrar, S., Deokhee, Y., Sutton, M., Chalkley, M., Sussex, J. and Scott, A. (2009) Has payment by results affected the way that English hospitals provide care? Difference-in-differences analysis. BMJ, 2009, 339, b3047.

Feins, D., Holin, M.J. and Phipps, A.A. (1996) MTO: Moving to Opportunity for Fair Housing Demonstration. Program Operations Manual (Revised). Prepared for U.S. Department of Housing and Urban Development. Office of Policy Development and Research. Cambridge: ABT Associates.

Foden, M., Grimsley, M., Lawless, P. and Wilson, I. (2010) Linking interventions to outcomes in area regeneration: The New Deal for Communities Programme in England. Town Planning Review, 81, 2, 151-172.

Gosling, V.K. (2008) Regenerating Communities: Women's Experiences of Urban Regeneration. Urban Studies, 45, 607.

Green, A.E. and Owen, D. (1998) Where are the jobless? Changing unemployment and non employment in cities and regions. Bristol/York: The Policy Press/JRF.

Gutiérrez-Romero, R. and Noble, M. (2008) Evaluating England's 'New Deal for Communities' programme using the difference-in-difference method. Journal of Economic Geography, 8, 759-778.

Heyman, B., Harrington, B., Heyman, A. and the National Energy Action Research Group (2011) A randomised controlled trial of an energy efficiency intervention for families living in fuel poverty. Housing Studies, 26, 1, 117-32.

Huxley, P., Evans, S., Leese, M., Gately, C., Rogers, A., Thomas, R. and Robson, B. (2004) Urban regeneration and mental health. Social Psychiatry and psychiatric epidemiology, 39, 280-285.

Jackson, G., Thornley, S., Woolston, J., Papa, D., Bernacchi, A. and Moore, T. (2011) Reduced acute hospitalisation with the healthy housing programme. J Epidemiol Community Health, 65, 7, 588-93.

Kearns, A., Bond, L. and Tannahill, C. (2009) Regeneration and health: Conceptualising the connections. Journal of Urban Regeneration and Renewal, 3, 1, 56-76. 
p. 26. Estimating the Impacts of Area Regeneration Programmes in Scotland on Health and Unemployment: a quasi-experimental approach

Lawless, P. (2006) Area-based urban interventions: rationale and outcomes: the New Deal for Communities Programme in England. Urban studies, 43, 11, 1991-2011.

Lawless, P., Foden, M., Wilson, I. and Beatty, C. (2008) Understanding Area-based Regeneration: The New Deal for Communities Programme in England. Urban Studies, 47, 2, 257-275.

Lawless, P. (2012) Can area-based regeneration programmes ever work? Evidence from England's New Deal for Communities Programme. Policy Studies, 33, 4, 313 328. DOI: 10.1080/01442872.2012.694639.

Lawless, P. (2013) Reconciling "Bottom-Up" Perspectives with "Top-Down” Change Data in Evaluating Area Regeneration Schemes. European Planning Studies, 21, 10, 1562-1577. DOI: 10.1080/09654313.2012.722959.

Leuven, EM, Sianesi, B. (2003) PSMATCH2: Stata Module to Perform Full Mahalanobis and Propensity Score Matching, Common Support Graphing, and Covariate Imbalance Testing. Boston College Department of Economics. Available at: https://EconPapers.repec.org/RePEc:boc:bocode:s432001

Leventhal, T. and Brooks-Gunn, J. (2003) Moving to Opportunity: an Experimental Study of neighbourhood Effects on Mental Health. American Journal of Public Health. 93, 9, 1576-1582.

Leyland, A, H. (2010) Methodological challenges in the evaluation of community interventions. European Journal of Public Health, 20, 3, 242-243.

Luellen, J.K., Shadish, W.R. and Clark, M.H. (2005) Propensity Scores: An Introduction and Experimental Test. Evaluation Review, 29, 6, 530-58.

Maidment, C.D., Jones, C.R., Webb, T.L., Hathway, E.A. and Gilbertson, J.M. (2014) The impact of household energy efficiency measures on health: a meta-analysis. Energy Policy, 65, 583-93.

Mathers, J., Parry, J. and Jones, S. (2008) Exploring Resident (Non)- Participation in the U.K. New Deal for Communities Regeneration Programme. Urban Studies, 45, 3, 591-606.

McCarthy, J. (2007) Partnership, Collaborative Planning and Urban Regeneration. London: Routledge.

McCartney, G., Hearty, W., Taulbut, M., Mitchell, R., Dryden, R. and Collins, C. (2017) Regeneration and health: a structured, rapid literature review. Public Health, 148, 69-87. DOI:10.1016/j.puhe.2017.02.022.

ODS Consulting (2006) An Overview of the Social Inclusion Partnership (SIP) programme: A report to Communities Scotland. Edinburgh: Scottish Executive.

Parry, J.M. (2004) Mechanisms by which area-based regeneration programmes might impact on community health: a case study of the New Deal for Communities initiative. Journal of Public Health, 118, 496-505.

Payne, N. and Saul, C. (2000) What common disorders do those reporting limiting longterm illness experience, and what is their survival and health service utilization experience? Journal of Public Health Medicine, 22, 3, 324-9.

Petticrew, M. (2013) Public health evaluation: epistemological challenges to evidence production and use. Evidence \& Policy, 9, 1, 87-95. DOl: 10.1332/174426413X663742.

Petticrew, M., Kearns, A., Hoy, C., Gibson, M. and Mason, M. (2008) The SHARP Study: Objectives, Design and Methodology. Scottish Government Social Research. Available from: www.scotland.gov.uk/socialresearch

Petticrew, M., Cummins, S., Ferrell, C., Findlay, A., Higgins, C., Hoy, C., Kearns, A. and Sparks, L. (2005) Natural experiments: an underused tool for public health? Journal of the Royal Institute of Public Health, 119, 751-757.

Ploegmakers, H. and Beckers, P. (2015) Evaluating urban regeneration: An assessment of the effectiveness of physical regeneration initiatives on run-down industrial sites in the Netherlands. Urban Studies, 52, 12, 2151-2169. 
p. 27. Estimating the Impacts of Area Regeneration Programmes in Scotland on Health and Unemployment: a quasi-experimental approach

Popay, J., Dibben, C., Halliday, E., Nazroo, J., Povall, S., Stafford, M., Walthery, P., Whitehead, M., Carr-Hill, R., Dixon, P. and Badlands, H. (2015) The impact on health inequalities of approaches to community engagement in the New Deal for Communities regeneration initiative: a mixed-methods evaluation. Public Health Research, 3, 12.

Rhodes, J., Tyler, P. and Brennan, A. (2005) Assessing the effects of area-based initiatives on local area outcomes: some thoughts based on the national evaluation of the Single Regeneration Budget in England. Urban Studies, 42, 11, 1919-1946.

Roberts, P.W. and Sykes, H. (2000) Urban Regeneration: A handbook. London: Sage.

Ruijsbroek, A., Wong, A., Kunst, A.E., van den Brink, C., van Oers, H.A.M., Droomers, M. and Stronks, K. (2017) The impact of urban regeneration programmes on health and health-related behaviour: Evaluation of the Dutch District Approach 6.5 years from the start. PLOS ONE, 12, 5, e0177262. Available at: https://doi.org/10.1371/journal.pone.0177262

Stafford, M., Nazroo, J., Popay, J.M. and Whitehead, M. (2008) Tackling Inequalities in Health: Evaluating the New Deal for Communities Initiative. Journal of Epidemiology and Community Health, 62, 4, 298-304.

Stafford, M., Badland, H., Nazroo J, Halliday, E., Walthery, P., Povall, S., Dibben, C., Whitehead, M. and Popay, J. (2014) Evaluating the health inequalities impact of area-based initiatives across the socioeconomic spectrum: a controlled intervention study of the New Deal for Communities, 2002-2008. J Epidemiol Community Health, 68, 10, 979-86.

Taylor, P. (2002) Social inclusion Partnerships: Factsheet. From notes originally contributed to seminar. Glasgow University, Department of Urban Studies, November 1998). Available at: https://peterdtaylorblog.wordpress.com/published-documents/social-inclusionpartnerships-factsheet/

Taylor, P., Turok, I. and Hastings, A. (1999) An Examination of Unsuccessful Priority Partnership Area Bids - Research Findings. Scottish Government. Available at: https://www2.gov.scot/Publications/1999/09/99a2185b-179f-476f-bf17d9b55e2fa8b7

Thomson, H., Atkinson, R., Petticrew, M. and Kearns, A. (2006) Do Urban Regeneration Programmes Improve Public Health and Reduce Health Inequalities? A Synthesis of the Evidence From U.K. Policy and Practice From (1980- 2004). Journal of Epidemiology and Community Health, 60, 2, 108-115.

Thomson, H., Morrison, D. and Petticrew, M. (2007) The health impacts of housing-led regeneration: a prospective controlled study. Journal of Epidemiology and Community Health, 61, 211-214.

Thomson, H. (2008) A dose of realism for healthy public policy: lessons from areabased initiatives in the UK. J Epidemiol Community Health, 62, 932-936.

Turok, I. (2004) Scottish Urban Policy: Continuity, Change and Uncertainty PostDevolution In: Johnstone, C. and Whitehead, M. (eds.) New Horizons in British Urban Policy: Perspectives on New Labour's Urban Renaissance. Aldershot: Ashgate: 111-128.

Turok, I. and Edge, N. (1999) The Jobs Gap in Britain's Cities: Employment Loss and Labour Market Consequences. Bristol: The Policy Press.

Tyler, P., Warnock, C., Begg, H., Brennan, A., Rhodes, J. and Stevens, S. (2001) National evaluation of the former regeneration programmes. Scottish Executive Central Research Unit.

Walthery, P., Stafford, M., Nazroo, J., Whitehead, M., Dibben, C., Halliday, E., Povall, S. and Popay, J. (2015) Health trajectories in regeneration areas in England: the impact of the New Deal for Communities intervention. J Epidemiol Community Health, 69, 762-768. 
p. 28. Estimating the Impacts of Area Regeneration Programmes in Scotland on Health and Unemployment: a quasi-experimental approach

Webster, D. (1994) Home and Workplace in the Glasgow Conurbation. Glasgow: Housing Department, Glasgow City Council.

Webster, D. (2000) Scottish Social Inclusion Policy: A Critical Assessment. Scottish Affairs, 30, 30-50.

Webster, D. (2002) Urban regeneration under devolution: inheritance and prospects. Fraser of Allander Institute Quarterly Economic Commentary, 27, 4, 40-46.

Whitley, R. and Prince, M. (2006) Can urban regeneration programmes assist coping and recovery for people with mental illness? Suggestions from a qualitative case study. Health Promotion International, 21, 1, 19-26. Available at: https://doi.org/10.1093/heapro/dai024

Ying Ho, S. (1999) Evaluating Urban Regeneration programmes in Britain: Exploring the Potential of the Realist Approach. Evaluation, 5, 4, 422-438. 